\title{
MRI findings in spinal cord injury patients who have respiratory distress
}

\author{
H Yamamoto, H Nakagawa, K Iwata
}

Department of Neurological Surgery, Aichi Medical University, Nagakute-cho, Aichi-gum, Aichi-ken, Japan 480-11.

The present study is an attempt to determine the prognostic capability of magnetic resonance imaging (MRI) in patients with a spinal cord injury (SCI) in the acute phase. The overall management of SCI patients is a prime consideration, and special precautions are required when the patient has respiratory distress. Twelve patients with a complete cervical injury accompanied by respiratory distress were examined by MRI, and a correlation of the MRI findings and the respiratory problems were investigated. In three cases with severe respiratory distress, the SCI was present above the C4-5 level, and MRI showed a high signal intensity at the upper C3. The severity of the respiratory failure was well correlated with the upper margin of the high signal intensity on T2-weighted images.

Keywords: spinal cord injury; MRI; respiratory distress.

\section{Introduction}

The conventional methods for the diagnosis of spinal cord injuries are plain x-rays, tomography, computed tomography (CT) and myelography, and there has been no direct means to visualise the cord injury itself, until the advent of magnetic resonance imaging (MRI). It is now possible to confirm the presence of spinal cord contusion, oedema or haematomyelia. ${ }^{1-5}$

The present study is an attempt to determine the prognostic capability of MRI in patients with SCI in the acute phase. We also investigated the effectiveness of GdDTPA enhanced MRI. The overall management of the patient is a prime consideration in the treatment of SCI. Special precautions are necessary when a patient suffers from a respiratory impairment. But a respiratory problem by no means always occurs immediately following SCI. Thus, we focused especially on the MRI findings of patients in whom respiratory distress occurred after SCI.

The subjects of the study were 39 patients diagnosed with a SCI in the acute phase by MRI in our department. There were 33 males and six females, ranging in age from 16 to 80 years, with a mean age of 46 years.
The injury site was cervical in 36 cases, thoracic in two cases, and lumbar in one case. Neurologically, 21 patients had a complete injury and 18 incomplete.

Of the 21 patients with a complete spinal cord injury there were 18 who had a cervical cord injury. Twelve of the 18 patients required a tracheotomy or the use of a respirator because of respiratory difficulty. The lesion was above $\mathrm{C} 4-5$ in four cases and below C5-6 in eight cases, complicated with ossification of the posterior longituding ligament (OPLL) in two cases, and spinal canal stenosis in one case (Tables I, II).

\section{Methods}

Picker VISTA (0.5 T) and Hitachi G-50 (0.5 T) were the main MRI systems used. The sagittal sections of $\mathrm{T} 1$ - and $\mathrm{T} 2$-weighted images were examined by the spin echo method. In the Gd-DTPA enhanced MRI, T1-weighed images were used in 22 cases with a spinal cord injury in the acute phase. The imaging effectiveness and utility of the Gd-DTPA were investigated from the acute to chronic phase, including 10 patients with apparent respiratory distress.

A portable respirator was immediately 
Table I The level of complete cervical injury vs respiratory distress

\begin{tabular}{|c|c|c|c|c|}
\hline \multirow[t]{2}{*}{ Level of cord injury } & \multirow[t]{2}{*}{ Respiratory distress (-) } & \multicolumn{2}{|c|}{ Respiratory distress $(+)$} & \multirow[t]{2}{*}{ Total } \\
\hline & & Mild & Severe & \\
\hline C3-4 & & & 1 & 1 \\
\hline C4-5 & 1 & & 2 & 3 \\
\hline C5-6 & 3 & 7 & & 10 \\
\hline \multirow[t]{2}{*}{ C6-7 } & 2 & 2 & & 4 \\
\hline & & 9 & 3 & \\
\hline Total & 6 & & 12 & 18 \\
\hline
\end{tabular}

Table II Complete cervical cord injury with respiratory distress

\begin{tabular}{|c|c|c|c|c|c|c|c|c|c|c|c|}
\hline \multirow[t]{3}{*}{ Case } & \multirow[t]{3}{*}{ Diagnosis } & \multicolumn{6}{|c|}{ MRI } & \multirow[t]{3}{*}{$\mathrm{OP}$} & \multirow[t]{3}{*}{ Outcome } & \multirow[t]{3}{*}{ Tracheotomy } & \multirow[t]{3}{*}{ Respirator } \\
\hline & & \multicolumn{2}{|c|}{ Acute } & \multicolumn{2}{|c|}{ Subacute } & \multicolumn{2}{|c|}{ Chronic } & & & & \\
\hline & & $\mathrm{P}$ & G & $\mathrm{P}$ & G & $\mathrm{P}$ & G & & & & \\
\hline $156 \mathrm{M}$ & Disc with narrow canal & + & + & & & + & + & + & $A-A$ & + & + \\
\hline $257 \mathrm{M}$ & C4-5 fracture-dislocation & + & + & & & + & + & + & $\mathrm{A}-\mathrm{A}$ & + & + \\
\hline $378 \mathrm{M}$ & C4-5 fracture-dislocation & + & - & & & & & - & A-died & + & + \\
\hline $420 \mathrm{M}$ & C5-6 fracture-dislocation & + & + & & & & & + & $A-A$ & + & + \\
\hline $548 \mathrm{~F}$ & C5-6 fracture-dislocation & & & + & + & + & - & + & $A-A$ & + & + \\
\hline $652 \mathrm{M}$ & C5-6 fracture-dislocation & + & + & & & + & + & + & $A-A$ & + & - \\
\hline $752 \mathrm{M}$ & C5-6 fracture-dislocation & + & + & & & + & + & + & $A-A$ & + & + \\
\hline $850 \mathrm{M}$ & C6-7 fracture-dislocation & + & + & & & + & + & + & $A-A$ & + & - \\
\hline $952 \mathrm{M}$ & C7 compression fracuture & + & + & & & + & + & + & $A-A$ & - & + \\
\hline $1053 \mathrm{M}$ & Fracture C5 & + & + & & & + & + & - & $A-A$ & + & + \\
\hline $1159 \mathrm{~F}$ & OPLL C2-5 & + & - & & & & & - & $A-A$ & + & + \\
\hline $1261 \mathrm{~F}$ & OPLL C2-6 & + & + & & & + & + & + & $A-B$ & + & + \\
\hline
\end{tabular}

aby Frankel's classification ${ }^{6}$

$P=$ plain. $G=G d-D T P A$ enhanced. 
available during the MRI examination. The acute phase MRI examinations were considered to be those performed within a week following the injury (but mostly on the day of the injury), while the chronic phase MRI examinations were conducted within a month after the injury.

\section{Results}

In the acute phase MRI, the T1-weighted image was favourable, making it possible to visualise a high resolution form of the cord or spine. The spinal cord could be delineated at an iso or low intensity, but good visualisation of such cord injury was infrequent. The T2-weighted images in the acute phase were inferior in resolution to the T1-weighted images, but the spinal cord injury could be sensitively delineated at a high signal intensity. Over the two vertebral levels all patients with an extensive high signal intensity area had a complete injury, virtually none showing any improvement. Within one vertebral level, all patients showing a focal high signal intensity showed moderate clinical recovery. The changes within the spinal cord in the T2-weighted images were a.useful prognostic indicator reflecting a poor prognosis.

The Gd-DTPA enhanced MRI was done in 22 patients, but none showed any imaging effectiveness in the acute phase, therefore it seemed to be of little clinical significance. The maximum effectiveness was found with the enhanced MRI in the subacute phase, with minimum effectiveness in the chronic phase. Moreover, the prognosis was poor in patients who showed good enhancement imaging.

Three of the 22 patients who had respiratory distress required a respirator. The level of injury was $\mathrm{C} 3-4$ in one case (traumatic disc herniation with developmental narrow canal) and C4-5 in two other cases (cervical fracture-dislocation). Two patients were eventually taken off the respirator after a relatively long period of respiratory physical therapy, 80 and 150 days respectively. A 78 year old male with a C4-5 injury died of pneumonia 10 days after the injury.

The respiratory impairment was relatively mild in those with a spinal cord injury below the C5-6 level. Even if a tracheotomy or a respirator was needed temporarily, for example, for up to 2 weeks, spontaneous respiration never disappeared, and the patient was eventually able to breathe unassisted.

No matter the security of the respiratory problem, acute phase MRI T2-weighted images showed a high signal intensity within the spinal cord. In those with a complete spinal cord injury, there was a high signal intensity over an extensive area. There was also a good correlation between the severity of the respiratory distress and the upper border of the high signal intensity in the T2-weighted images. In three cases with a high signal intensity reaching C3 level there was severe respiratory distress. With chronic phase MRI, the site of the spinal cord injury was visualised as a Gd-DTPA enhanced lesion reaching the $\mathrm{C} 3$ level. Even in the severe cases, the respiratory problem did not occur immediately following the injury, but gradually progressed over $48-72 \mathrm{~h}$, when respiratory assistance became mandatory.

Two cases which recovered from severe respiratory distress are presented as follows:

\section{Case 1}

A 56 year old man became a quadriplegic immediately after a fall from a footstool about $1.5 \mathrm{~m}$ high and was transferred to our department $3 \mathrm{~h}$ later. On admission he was alert and normally oriented, with a flaccid quadriplegia below the deltoid muscles. The pathological reflexes were not elicited. Sensory function was absent below the $\mathrm{C} 4$ dermatomes bilaterally. At this point, his respiration was spontaneous and of an abdominal type, but he had slight dyspnea. The cervical x-ray showed a developmentally narrow canal and a slight malalignment (Fig 1a). The T1-weighted image of the acute phase MRI showed cord compression due to disc protrusion at $\mathrm{C} 3-4$ and $\mathrm{C} 4-5$ levels (Fig 1b). The T2-weighted image showed a high signal intensity within the cord at $\mathrm{C} 3$ and $\mathrm{C} 4$ (Fig 1c). Forty-eight hours after injury, his conscious level deteriorated due to respirarory distress, and a respirator was installed. $\mathrm{He}$ received active pulmonary therapy and was successfully weaned off the respirator 80 days later. After examination, anterior microdiscectomies with bony fusion were performed at the 
a

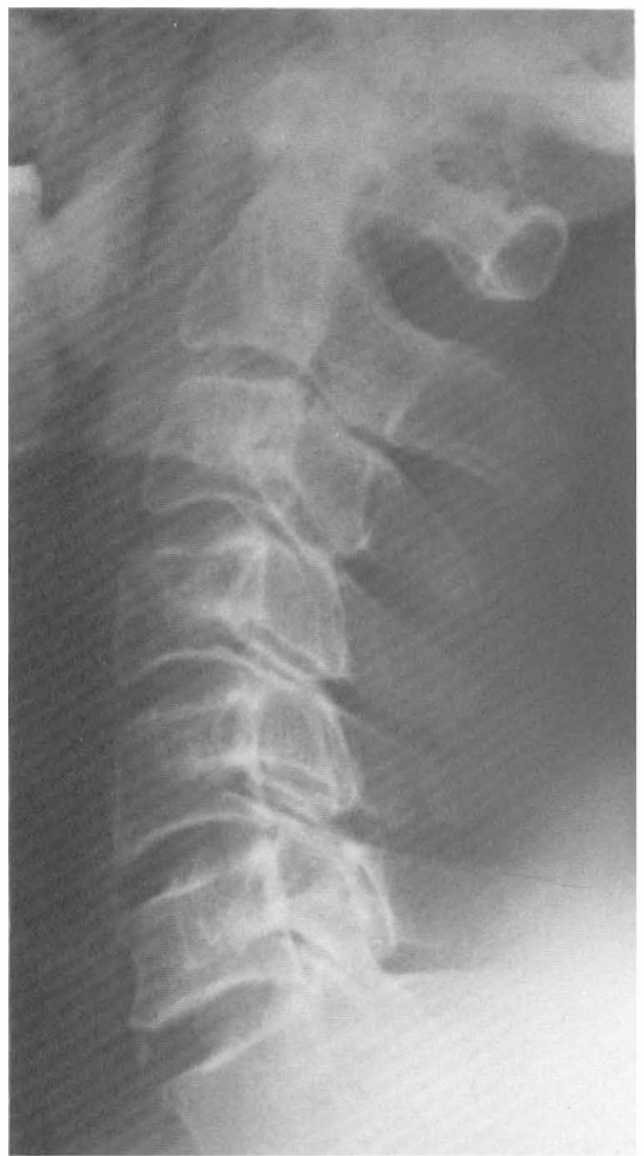

c

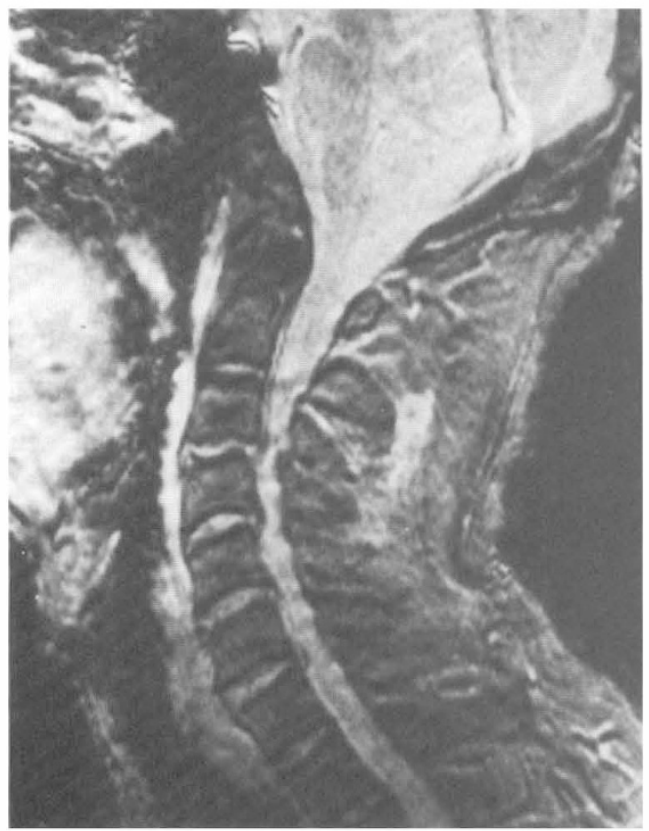

b

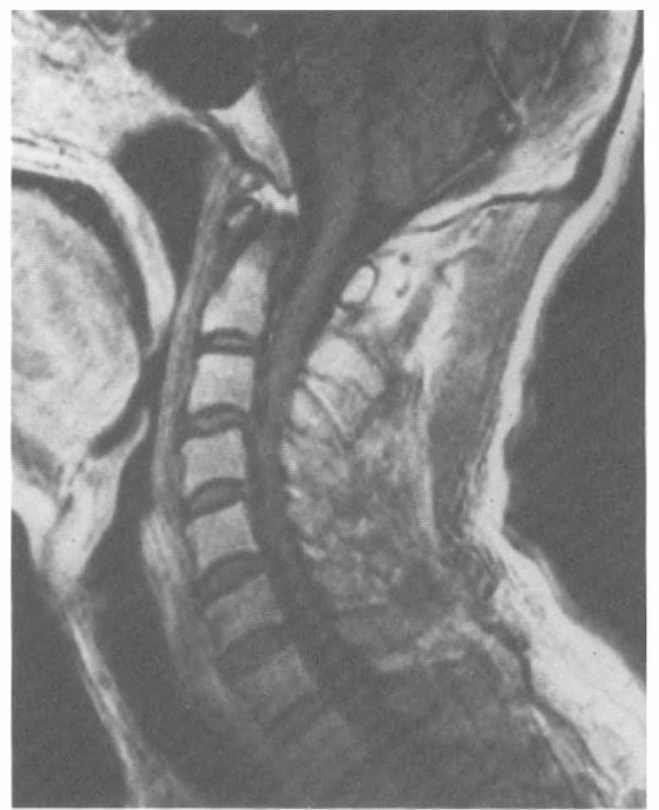

d

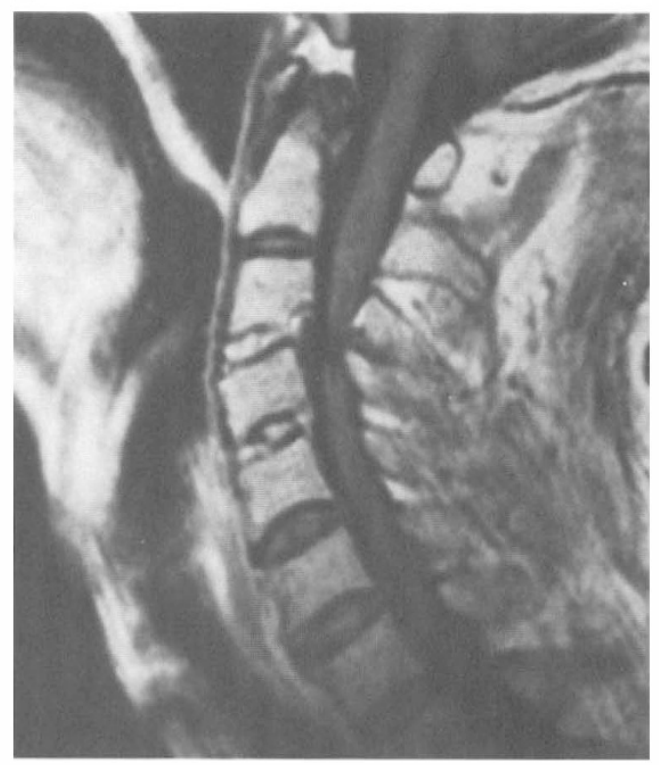

Figure 1 (a) The cervical $x$-ray showed narrow canal and slight malalignment. (b) T1-weighted image of acute phase MRI with cord compression due to disc protrusion at $\mathrm{C} 3-4$ and $\mathrm{C} 4-5$. (c) T2-weighted image showed high signal intensity in the cord to $\mathrm{C} 3$ portion. (d) In chronic phase MRI showed cord atrophy at C3-4. 
C3-4 and C4-5 levels. The chronic phase MRI showed cord atrophy at C3-4 (Fig 1d).

\section{Case 2}

This 57 year old man developed complete quadriplegia immediately after a fall from a construction site about $4 \mathrm{~m}$ high, and was brought to our department $2 \mathrm{~h}$ later. On admission he was alert and well oriented with a bruise on his forehead. Neurological examination revealed flaccid quadriplegia with weakness of the biceps and deltoid, areflexia, and anaesthesia below the $\mathrm{C} 4$ dermatomes bilaterally. His respiration was weak and abdominal in type. $\mathrm{He}$ was dyspnoeic. He required a respirator for some 150 days. After delicate but tedious respiratory treatment, spontaneous respiration began to appear. Cervical $\mathrm{x}$-ray had shown a fracture-dislocation at C4-5 (Fig 2a). The T1weighted image of the acute phase MRI showed severe cord compression due to dislocation and a disc protrusion at $\mathrm{C} 4-5$ (Fig 2b). The high signal intensity of the cord was evident from $\mathrm{C} 3$ to $\mathrm{C} 6$ on the T2-weighted image (Fig 2c).

\section{Discussion}

With the emergence of MRI, direct visualisation of a spinal cord injury is feasible through changes in high signal intensity within the spinal cord. The high signal intensity in the spinal cord makes it possible to speculate on the prognosis of SCI patients. $^{4,5}$

The highly sensitive delineation by $\mathrm{T} 2$ weighted images proved effective for an appreciation of the prognosis, showing intramedullary changes in the cord. With the acute phase T2-weighted images, the injured cord can be visualised as a high signal intensity area. All patients with this recognisable and extensive high signal intensity over more than two vertebral levels formed a complete injury group: in the chronic phase the spinal cord showed myelomalacia, and the T1-weighted images revealed a low intensity. The widespread high signal intensity indicated severe spinal cord trauma, and was indicative of a poor prognosis. Chakeres et al and Schouman-Claeys both experimented with acute phase spinal cord injury in dogs. Using a 0.5 tesla MRI, they reported from T2-weighted images that a changing high signal intensity indicated the presence of petechial haemorrhages and oedema. ${ }^{7,8}$

All patients with respiratory distress had a complete spinal cord injury and had clearcut and extensive high signal intensity areas on MRI. The injured level in three severe cases was $\mathrm{C} 3-4$ in one case, and $\mathrm{C} 4-5$ in two cases. Those who sustained a spinal cord injury below C5-6 level had a mild respiratory problem. The severity of the respiratory distress correlated well with the upper border of the high signal intensity on T2-weighted images. In three cases where the high signal border impinged on C3, there was severe respiratory trouble. In the chronic phase, the MRI-indicated locus of the spinal cord injury in these cases reached the $\mathrm{C} 3$ level and was also visualised by the Gd-DTPA enhanced MRI. The breathing difficulty in severely involved patients occurred not just after the actual injury but could develop 48-72 h later, and then required respiratory assistance. This also illustrated the effectiveness of MRI carried out very soon after the injury.

There was significant recovery in all cases in which the high signal intensity was located focally within one vertebral level. The fact that these cases in the chronic phase showed a disappearance of the high signal intensity suggested that patients with the focal high signal intensity have a moderate recovery of the spinal cord trauma with oedema, reflecting possible recovery. Kuldarni et al and Boundurant et al used 1.5 tesla MRI for acute phase spinal cord injury, and suggested that a low signal intensity by T2-weighted images indicates haematomyelia. Reports of such cases have indicated that there is no recovery. ${ }^{9-11}$

Hackney et al and Weirich et al used MRI in their experiments involving spinal cord injury in the rat, only to find that a low signal intensity in the acute phase is indicative of the development of the haemoglobin acidification process. ${ }^{12,13}$ In our cases, the T2-weighted images in the acute-phase MRI revealed only a high signal intensity area, and a low signal intensity region was found in cases of complete injury with a poor prognosis. We most often used MRI with 0.5 tesla, so that the resulting low resolution 
threshold presumably made the delineation of the low signal intensity impossible.

On the other hand, the resolution of T1-weighted imaging in the acute phase was favourable, which was effective for the diagnosis of morphological changes in the spinal cord and vertebra. However, it could not serve as a prognostic indicator. GdDTPA enhancement proved virtually ineffective for visualisation in the acute phase no matter what the neurological condition was. Visualisation was maximal in the subacute phase, but poor in the chronic phase. The enhancement effect suggests extravascular leakage or contrast agent or vascular degeneration, But even where there was

a

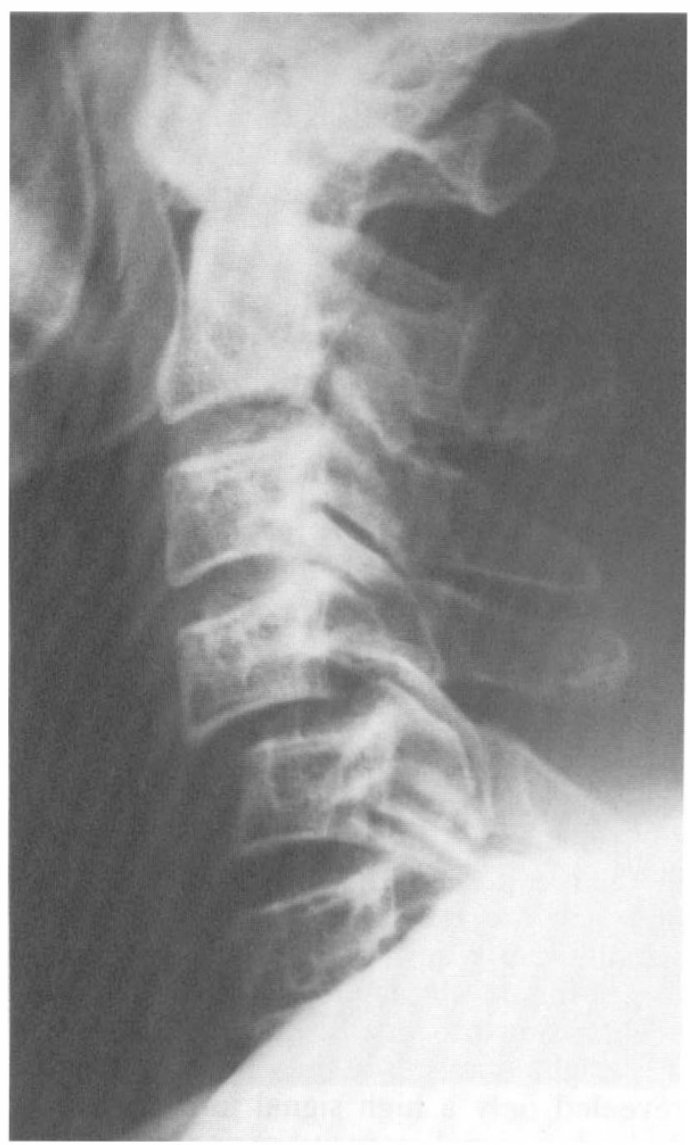

b

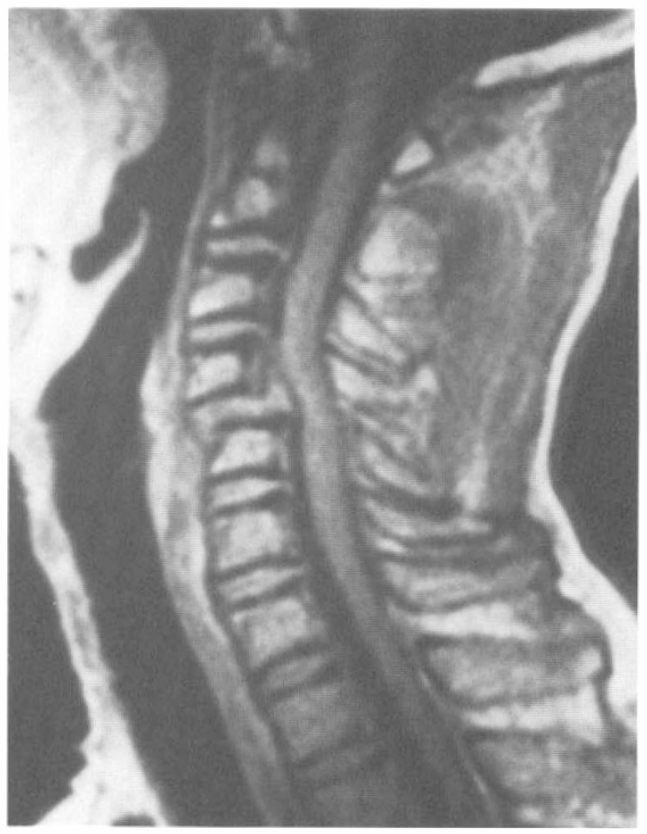

c

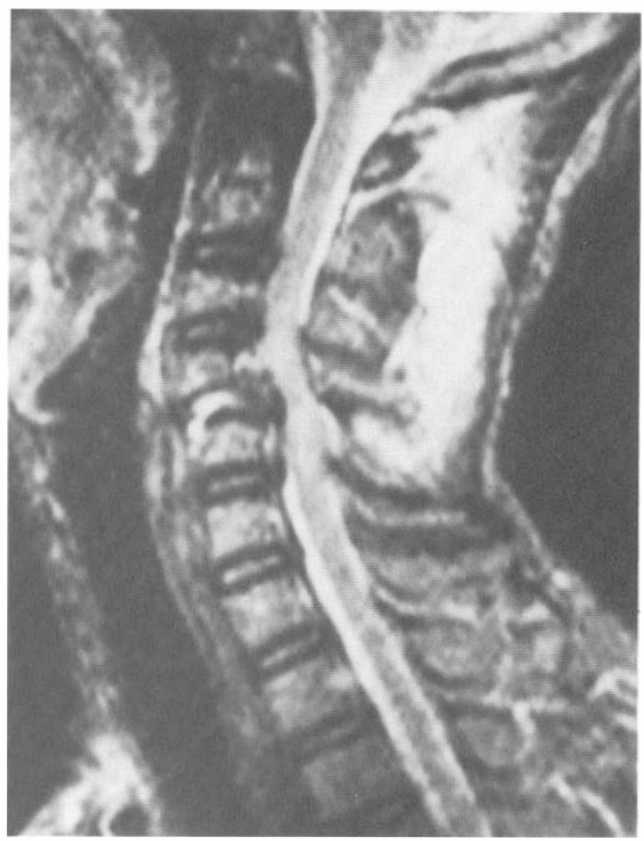

Figure 2 (a) The cervical $x$-ray showed fracture-dislocation at C4-5. (b) T1-weighted image of acute phase MRI showed severe cord compression due to dislocation and disc protrusion at $\mathrm{C} 4-5$. (c) The high signal intensity in the cord from $\mathrm{C} 3$ to $\mathrm{C} 6$ appeared on the T2-weighted image. 
good visualisation, the prognosis was poor. While it proved to be an effective prognostic indicator and helped to estimate the condition in the subacute phase, it was at the same time a sign for a poor outcome. MRI was also effective in delineating a tiny lesion in the spinal cord.

\section{Conclusions}

MRI was used in cases of complete cervical injury accompanied by respiratory distress in 12 patients, and the MRI findings and respiratory problems were investigated.

In three severe cases complicated by respiratory difficulty, the spinal cord injury was above the $\mathrm{C} 4-5$ level.

In the acute phase MRI, the high signal intensity in the spinal cord was extensive and reached $\mathrm{C} 3$ in those patients who required a respirator because of respiratory failure.

In patients in whom a high signal was found below $\mathrm{C} 4$, there was transient respiratory distress, the respiration was abdominal in type, and continuous care was required.

The severity of the injury and the upper border of the high signal intensity on the T2-weighted images were well correlated in patients with respiratory distress. A prognostic indicator is therefore the T2-weighted images in the acute phase.

\section{References}

1 Kadoya S, Nakamura T, Kobayashi S, Yamamoto I (1987) Magnetic resonance imaging of acute spinal cord injury. Neuroradiology 29: 252-255.

2 Mirvis SE, Geisler FH, Jelinek JJ, Joslyn JN, Gellad F (1988) Acute cervical spine trauma: Evaluation with 1.5 MR imaging. Radiology 166: 807-816.

3 Quencer RM, Sheldon JJ, Donovan Post MJ, Diaza RD, Montalvo BM, Green BA et al (1986): MRI of the chronically injured cervical spinal cord. AJR 147: 125-132.

4 Yamamoto H, Nakagawa H, Iwata K, Yuasa H, Okumura T, Hoshino D (1989) Usefulness of MRI in spinal injuries. Neurotraumatology (Tokyo) 12: 76-81.

5 Yamamoto H, Nakagawa H, Iwata K (1992) Magnetic resonance imaging of acute spinal cord injury. Progress in CI 14(2): 155-160.

6 Frankel HL, Hancock DO, Hyslop G, Melzak J, Melzak J, Michaelis LS, et al (1969) The value of postural reduction in the initial management of closed injuries of the spine with paraplegia and tetraplegia. Paraplegia 7: 179-192.

7 Chakeres DW, Flickinger F, Bresnahan JC, Beattie MS, Weiss KL, Miller C et al (1987) MR imaging of acute spinal cord trauma. AJNR 8: 5-10.

8 Schouman-Claeys E, Frija G, Cuenod CA, Begon D, Paraire F, Martin V (1990) MR imaging of acute spinal cord injury: Result of an experimental study in dogs. AJNR 11: 959-965.

9 Kulkarni MV, Mcardie CB, Kopanickey D, Miner M, Cotler HB, Lee KF et al (1987) Acute spinal cord injury: MR imaging at 1.5T. Radiology 164: 837-843.

10 Bondurant FJ, Cotler HB, Kulkarni MV, McArdle CB, Harris JH (1990) Acute spinal cord injury; A study using physical examination and magnetic resonance imaging. Spine 15: 161-168.

11 Kulkarni MV, Bondurant FJ, Rose SL, Narayana PA (1988) 1.5 tesla magnetic resonance imaging of acute spinal cord trauma. Radiographics 8: 1059-1082.

12 Hackney DB, Asato R, Joseph PM, Carvlin MJ, McGrath JT, Grossman RI et al (1986) Hemorrhage and edema in acute spinal cord compression: Demonstration by MR imaging. Radiology 161: 387-390.

13 Weirich SD, Cotler HB, Narayana PA, Hazle JD, Jackson EF, Coupe KJ et al (1990) Histopathological correlation of magnetic resonance imaging signal patterns in a spinal cord injury model. Spine 15: 630-638. 